\title{
Complete genome sequence of Marivirga tractuosa type strain $\left(\mathbf{H}-43^{\mathrm{T}}\right)$
}

\author{
Ioanna Pagani ${ }^{1}$, Olga Chertkov ${ }^{1,2}$, Alla Lapidus ${ }^{1}$, Susan Lucas ${ }^{1}$, Tijana Glavina Del Rio', \\ Hope Tice ${ }^{1}$, Alex Copeland ${ }^{1}$, Jan-Fang Cheng ${ }^{1}$, Matt Nolan ${ }^{1}$, Elizabeth Saunders ${ }^{1,2}$, Sam \\ Pitluck ${ }^{1}$, Brittany Held ${ }^{1.2}$, Lynne Goodwin ${ }^{1,2}$, Konstantinos Liolios ${ }^{1}$, Galina Ovchinikova ${ }^{1}$, \\ Natalia Ivanova ${ }^{1}$, Konstantinos Mavromatis ${ }^{1}$, Amrita Pati ${ }^{1}$, Amy Chen ${ }^{3}$, Krishna \\ Palaniappan ${ }^{3}$, Miriam Land ${ }^{1,4}$, Loren Hauser ${ }^{1,4}$, Cynthia D. Jeffries ${ }^{1,4}$, John C. Detter ${ }^{1,4}$, Cliff \\ Han $^{1,2}$, Roxanne Tapia ${ }^{1,2}$, Olivier D. Ngatchou-Djao ${ }^{5}$, Manfred Rohde ${ }^{5}$, Markus Göker ${ }^{6}$, \\ Stefan Spring ${ }^{6}$, Johannes Sikorski ${ }^{6}$, Tanja Woyke ${ }^{1}$, Jim Bristow ${ }^{1}$, Jonathan A. Eisen ${ }^{1,7}$, Victor \\ Markowitz $^{3}$, Philip Hugenholtz ${ }^{1,8}$, Hans-Peter Klenk ${ }^{6}$ and Nikos C. Kyrpides ${ }^{1 *}$ \\ ${ }^{1}$ DOE Joint Genome Institute, Walnut Creek, California, USA \\ ${ }^{2}$ Los Alamos National Laboratory, Bioscience Division, Los Alamos, New Mexico, USA \\ ${ }^{3}$ Biological Data Management and Technology Center, Lawrence Berkeley National \\ Laboratory, Berkeley, California, USA \\ ${ }^{4}$ Oak Ridge National Laboratory, Oak Ridge, Tennessee, USA \\ ${ }^{5}$ HZI - Helmholtz Centre for Infection Research, Braunschweig, Germany \\ ${ }^{6}$ DSMZ - German Collection of Microorganisms and Cell Cultures GmbH, Braunschweig, \\ Germany \\ ${ }^{7}$ University of California Davis Genome Center, Davis, California, USA \\ ${ }^{8}$ Australian Centre for Ecogenomics, School of Chemistry and Molecular Biosciences, The \\ University of Queensland, Brisbane, Australia \\ *Corresponding authors: Nikos C Kyrpides
}

Keywords: mesophilic, chemoorganotrophic, strictly aerobic, Gram-negative, slender and flexible rod-shaped, non-sporeforming, motile by gliding, Flammeovirgaceae, GEBA

Marivirga tractuosa (Lewin 1969) Nedashkovskaya et al. 2010 is the type species of the genus Marivirga, which belongs to the family Flammeovirgaceae. Members of this genus are of interest because of their gliding motility. The species is of interest because representative strains show resistance to several antibiotics, including gentamicin, kanamycin, neomycin, polymixin and streptomycin. This is the first complete genome sequence of a member of the family Flammeovirgaceae. Here we describe the features of this organism, together with the complete genome sequence and annotation. The 4,511,574 bp long chromosome and the 4,916 bp plasmid with their 3,808 protein-coding and 49 RNA genes are a part of the Genomic Encyclopedia of Bacteria and Archaea project.

\section{Introduction}

Strain $\mathrm{H}-43^{\mathrm{T}}$ (= DSM 4126 = ATCC 23168 = NBRC 15989 ) is the type strain of the species Marivirga tractuosa. The genus Marivirga, whose type species is $M$. tractuosa, contains only one additional species: M. sericea. The generic name 'Marivirga' derives from Latin words 'mare', the sea and 'virga', rod, meaning 'a rod that inhabits marine environments' [1]. The species epithet 'tractuosa' is a Latin adjective meaning 'that draws to itself, gluey, viscous', probably referring to the phenotype of gliding motility [1]. Strain $\mathrm{H}-43^{\mathrm{T}}$ was isolated in
1969 from a beach sand sample collected from Nhatrang (South China Sea), Vietnam [2] and was initially named 'Microscilla tractuosa' by Lewin [3], but was never validly published under this name. The strain was then in 1974 joined to the genus Flexibacter by Leadbetter [4]. In 2010, strain $\mathrm{H}-43^{\mathrm{T}}$ was reclassified to the novel genus Marivirga, based on a polyphasic approach [1]. Other strains have been isolated worldwide from mud in the Orne Estuary, France and silty sand in Penang, Malaysia [5], as well as from brown mud 
Pagani et al.

from Muigh Inis, Ireland, underneath frozen sand in the upper littoral zone at Auke Bay, Alaska, redbrown mud from Helgoland Island, Germany, and from brown sand at Moreton Bay, Australia [6]. These sampling sites suggest an ecological preference of $M$. tractuosa for wet terrestrial habitats $[1,2]$. Here we present a summary classification and a set of features for M. tractuosa strain $\mathrm{H}-43^{\mathrm{T}}$, together with the description of the complete genomic sequencing and annotation.

\section{Classification and features}

The 16S rRNA gene sequence of the strain $\mathrm{H}-43^{\mathrm{T}}$ shares the highest degree of similarity (99.1\%) with $M$. sericea, the only other member of the genus Marivirga (Figure 1) [12], and with an uncultured Bacteroidetes clone SHBC423 (99\%, GQ350249) from oceanic dead zones [13]. A representative genomic 16S rRNA gene sequence of $M$. tractuosa was compared using NCBI BLAST under default values with the most recent release of the Greengenes database [14] and the relative frequencies, weighted by BLAST scores, of taxa and keywords (reduced to their stem [15]) were determined. The five most frequent genera were Flexibacter $(=$ not yet renamed Marivirga hits) (26.8\%), Pontibacter
(21.6\%), Hymenobacter (21.4\%), Adhaeribacter (8.3\%) and Microscilla (8.0\%) (57 hits in total). The highest-scoring environmental sequence was EU447282 ('Flexibacteraceae bacterium KMM 6276 '), which showed an identity of $100.0 \%$ and an HSP coverage of $97.6 \%$, but most probably represents a Marivirga strain. The five most frequent keywords within the labels of environmental samples which yielded hits were 'microbi' (4.0\%), 'sediment' (3.1\%), 'site' (1.9\%), 'group' (1.7\%) and 'coral' (1.6\%) (192 hits in total). These keywords support the ecological preference of $M$. tractuosa for wet habitats, as deduced from the sampling sites of the cultivated strains. Environmental samples which yielded hits of a higher score than the highest scoring species were not found.

Figure 1 shows the phylogenetic neighborhood of M. tractuosa $\mathrm{H}-43^{\mathrm{T}}$ in a $16 \mathrm{~S}$ rRNA based tree. The sequences of the two identical 16S rRNA gene copies in the genome do not differ from the previously published 16S rRNA sequence (AB078072).

The cells of strain $\mathrm{H}-43^{\mathrm{T}}$ are long, slender and flexible rods $0.4-0.5 \mu \mathrm{m}$ in diameter and $10-50 \mu \mathrm{m}$ in length or longer (Figure 2). Strain $\mathrm{H}-43^{\mathrm{T}}$ is a Gramnegative non-spore-forming bacterium (Table 1) that exhibits gliding motility [1].

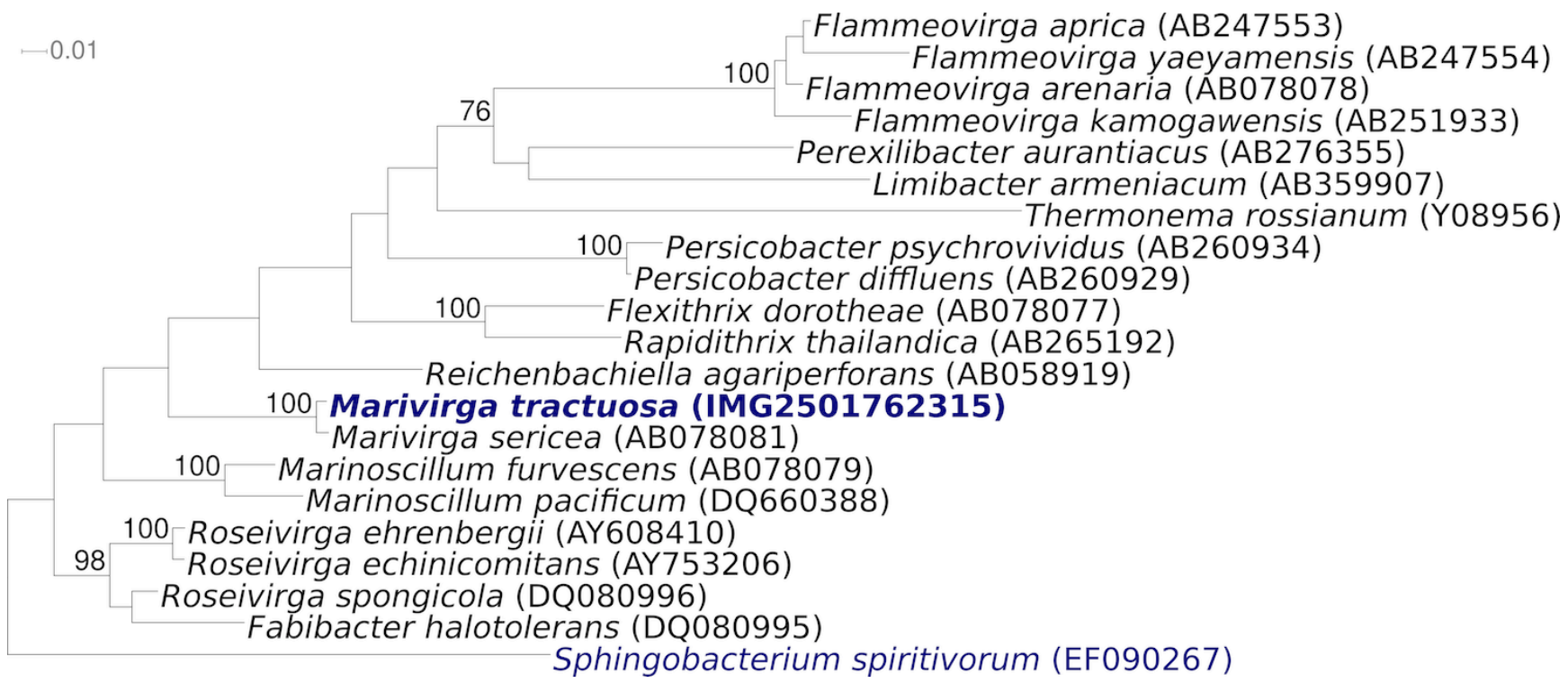

Figure 1. Phylogenetic tree highlighting the position of $M$. tractuosa relative to the other type strains within the family Flammeovirgaceae. The trees were inferred from 1,408 aligned characters $[7,8]$ of the $16 \mathrm{~S}$ rRNA gene sequence under the maximum likelihood criterion [9] and rooted in accordance with the family Sphingobacteriaceae. The branches are scaled in terms of the expected number of substitutions per site. Numbers above branches are support values from 1,000 bootstrap replicates [10] if larger than 60\%. Lineages with type strain genome sequencing projects registered in GOLD [11] are shown in blue, published genomes in bold. 
Strain $\mathrm{H}-43^{\mathrm{T}}$ is strictly aerobic and chemoorganotrophic [1]. Growth is observed at $10-40^{\circ} \mathrm{C}$ and with $0.5-10 \% \mathrm{NaCl}$, with optimal growth at $28-32^{\circ} \mathrm{C}$ and $4-7 \% \mathrm{NaCl}$ [1]. Colonies are circular, shiny and 2-4 $\mathrm{mm}$ in diameter after $72 \mathrm{~h}$ of incubation on marine agar [1]. They are usually dark-orange in color but whitish or yellow-pigmented variants may occur [1]. Pigment type three was found in the strain $\mathrm{H}-43^{\mathrm{T}}$, the main pigment being saproxanthin [2]. In $n$ hexane, the absorption maxima of the pigments from crude extract were $425 \mathrm{~nm}, 447 \mathrm{~nm}, 471 \mathrm{~nm}$ and $505 \mathrm{~nm}$ [2]. Flexirubin-type pigments are not produced. Arginine dihydrolase, ornithine decarboxylase, lysine decarboxylase and tryptophan deaminase activities were described to be absent [1], however, Srinivas et al. [22] found that strain $\mathrm{H}-43^{\mathrm{T}}$ could utilize arginine, and also that growth on alanine and cysteine was weak. Nitrate is not reduced. Indole and acetoin (Voges-Proskauer reaction) are not produced [1]. Gelatin, Tween 20, Tween 40, Tween 80 and DNA are hydrolyzed, as well as agar, starch, urea, cellulose (CM-cellulose and filter paper) and chitin [1,2], however, again in contrast to the original description [1], Srinivas et al. reported that the strain does not hydrolyze Tween 20 , Tween 40 or Tween 80 [22]. Acid is not produced from Larabinose, cellobiose, L-fucose, D-galactose, glycerol, lactose, melibiose, raffinose, L-rhamnose, L-sorbose, sucrose, trehalose, DL-xylose, N-acetylglucosamine, citrate, acetate, fumarate, malate, adonitol, dulcitol, inositol or mannitol. In the API $50 \mathrm{CH}$ gallery, acid is produced only from esculin and arbutin. Production of hydrogen sulfide and hydrolysis of casein are variable [1]. Citrate is utilized but lactose, inositol, glu- conate, caprate, phenylalanine and malonate are not. Utilization of arabinose, D-glucose, D-mannose, sucrose, mannitol, N-acetylglucosamine, maltose, adipate, malate and sorbitol is variable [1]. Glucose, glycerol, galactose and sucrose ( $5.1 \mathrm{~g} / \mathrm{l}$, each) are used as carbon sources and stimulate the growth of strain $\mathrm{H}-43^{\mathrm{T}}$, while sodium acetate and sodium lactate do not [2]. Nitrogen sources supporting growth include tryptone $(1 \mathrm{~g} / \mathrm{l})$ and casamino acids $(1 \mathrm{~g} / \mathrm{l})$, but not sodium glutamate or $\mathrm{NO}_{3}-$ [2]. Alkaline phosphatase, esterase (C4), esterase lipase (C8), leucine arylamidase, valine arylamidase, cystine arylamidase, $\alpha$ chymotrypsin, acid phosphatase, naphthol-AS-BIphosphohydrolase, $\beta$-galactosidase and $\alpha$ - and $\beta$ glucosidase activities are present, but lipase (C14), trypsin, $\alpha$-galactosidase, $\beta$-glucuronidase, $\mathrm{N}$-acetyl $\beta$ glucosaminidase, $\alpha$-mannosidase and $\alpha$-fucosidase activities are negative in the API ZYM gallery [1]. In litmus-milk, the dye was reduced and the clotting occurred. Moreover, litmus turned pink due to acidification and the curd was re-digested because of proteolysis [2]. Strain $\mathrm{H}-43^{\mathrm{T}}$ is sensitive to ampicillin $(10 \mu \mathrm{g})$, benzylpenicillin (10 $\mathrm{U})$, carbenicillin (100 $\mu \mathrm{g})$, chloramphenicol $(30 \mu \mathrm{g})$, doxycycline $(10 \mu \mathrm{g})$, erythromycin $(15 \mu \mathrm{g})$, lincomycin $(15 \mu \mathrm{g})$, oleandomycin $(15 \mu \mathrm{g})$ and tetracycline $(30 \mu \mathrm{g})$, but resistant to gentamicin $(10 \mu \mathrm{g})$, kanamycin $(30 \mu \mathrm{g})$, neomycin $(30 \mu \mathrm{g})$, polymixin $(300 \mathrm{U})$ and streptomycin $(30 \mu \mathrm{g})$ [1]. Cytochrome oxidase, catalase and alkaline phosphatase tests were positive [1], although Srinivas et al. [22] found only a weak reaction in the catalase test. When growing, the strain was able to degrade dihydroxyphenyl alanine and tyrosine (5 g/l) [2].

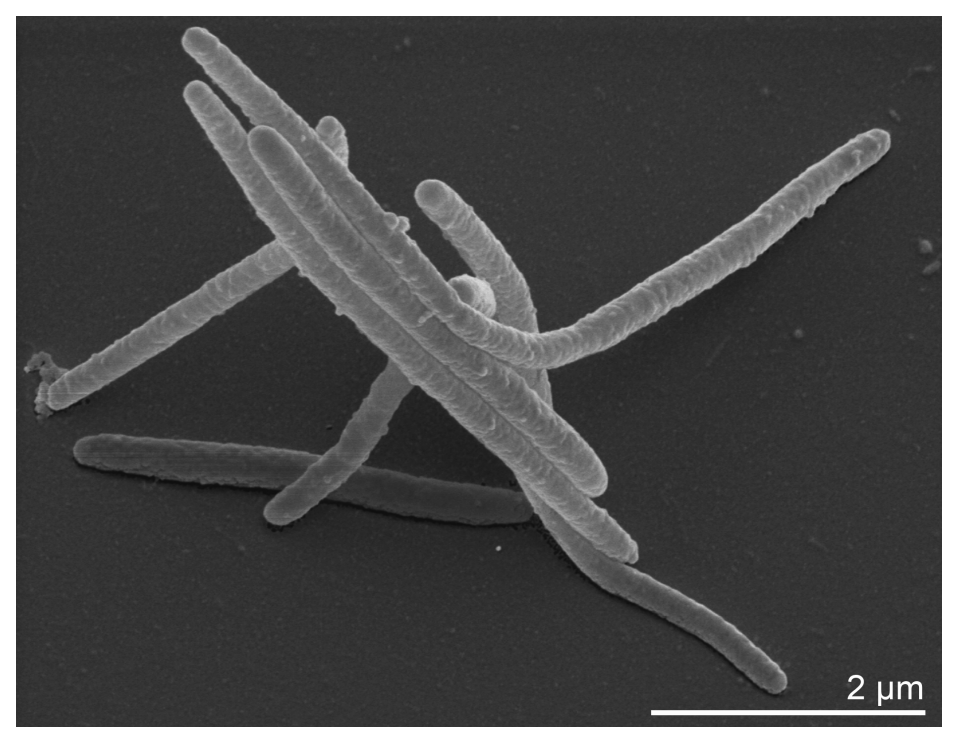

Figure 2. Scanning electron micrograph of $M$. tractuosa $\mathrm{H}-43^{\top}$ 
Table 1. Classification and general features of M. tractuosa $\mathrm{H}-43^{\top}$ according to the MIGS recommendations [16]

\begin{tabular}{|c|c|c|c|}
\hline MIGS ID & Property & Term & Evidence code \\
\hline & \multirow{8}{*}{ Current classification } & Domain Bacteria & TAS [17] \\
\hline & & Phylum Bacteroidetes & TAS [19] \\
\hline & & Class Sphingobacteria & TAS [18] \\
\hline & & Order Sphingobacteriales & TAS [18] \\
\hline & & Family Flammeovirgaceae & TAS [18] \\
\hline & & Genus Marivirga & TAS [1] \\
\hline & & Species Marivirga tractuosa & TAS [1] \\
\hline & & Type strain $\mathrm{H}-43$ & TAS [1] \\
\hline & Gram stain & negative & TAS $[1,2]$ \\
\hline & Cell shape & long, slender and flexible rods & TAS [1] \\
\hline & Motility & motile by gliding & TAS $[1,2]$ \\
\hline & Sporulation & no & TAS $[1,2]$ \\
\hline & Temperature range & $10^{\circ} \mathrm{C}-40^{\circ} \mathrm{C}$ & TAS [1] \\
\hline & Optimum temperature & $28^{\circ} \mathrm{C}-32^{\circ} \mathrm{C}$ & TAS $[1,2]$ \\
\hline & Salinity & $0.5 \%-10 \% \mathrm{NaCl}$ & TAS [1] \\
\hline \multirow{3}{*}{ MIGS-22 } & Oxygen requirement & strictly aerobic & TAS $[1,2]$ \\
\hline & Carbon source & glycerol, glucose, galactose, sucrose & TAS [2] \\
\hline & Energy metabolism & chemoorganotroph & TAS [1] \\
\hline MIGS-6 & Habitat & wet terrestrial habitats, occasionally fresh water & TAS [2] \\
\hline MIGS-15 & Biotic relationship & free-living & NAS \\
\hline \multirow[t]{3}{*}{ MIGS-14 } & Pathogenicity & not reported & NAS \\
\hline & Biosafety level & 1 & TAS [20] \\
\hline & Isolation & beach sand sample & TAS [1] \\
\hline MIGS-4 & Geographic location & Nhatrang (South China Sea), Vietnam & TAS [1] \\
\hline MIGS-5 & Sample collection time & 1969 or before & TAS [2] \\
\hline MIGS-4.1 & Latitude & 12.25 & \\
\hline MIGS-4.2 & Longitude & 109.20 & NAS \\
\hline MIGS-4.3 & Depth & not reported & NAS \\
\hline MIGS-4.4 & Altitude & not reported & NAS \\
\hline
\end{tabular}

Evidence codes - IDA: Inferred from Direct Assay (first time in publication); TAS: Traceable Author Statement (i.e., a direct report exists in the literature); NAS: Non-traceable Author Statement (i.e., not directly observed for the living, isolated sample, but based on a generally accepted property for the species, or anecdotal evidence). These evidence codes are from of the Gene Ontology project [21]. If the evidence code is IDA, then the property was directly observed by one of the authors or an expert mentioned in the acknowledgements

\section{Chemotaxonomy}

The predominant cellular fatty acid of the strain $\mathrm{H}-43^{\mathrm{T}}$ were iso- $\mathrm{C}_{15: 0}(36.8 \%)$, iso- $\mathrm{C}_{15: 1}(23.0 \%)$ and iso- $\mathrm{C}_{17: 03-\mathrm{OH}}(12.2 \%)$, with a detailed listing given in Nedashkovskaya et al. [1]. Srinivas et al. reported fundamentally different observations for strain $\mathrm{H}-43^{\mathrm{T}}$, with the $\mathrm{C}_{16: 0}(69 \%$ of the total fatty acids) to be the most important fatty acids in the strain $\mathrm{H}-43^{\mathrm{T}}$, whereas iso- $\mathrm{C}_{15: 0}$ was not detectable [22]. The main respiratory quinone is MK-7 [1].

\section{Genome sequencing and annotation Genome project history}

This organism was selected for sequencing on the basis of its phylogenetic position [23], and is part of the Genomic Encyclopedia of Bacteria and Archaea project [24]. The genome project is deposited in the Genomes On Line Database [11] and the complete genome sequence is deposited in GenBank. Sequencing, finishing and annotation were performed by the DOE Joint Genome Institute (JGI). A summary of the project information is shown in Table 2. 


\begin{tabular}{lll}
\multicolumn{2}{l}{ Table 2. Genome sequencing project information } \\
\hline MIGS ID & Property & Term \\
\hline MIGS-31 & Finishing quality & Finished \\
MIGS-28 & Libraries used & Three genomic libraries: one 454 pyrosequence standard library, \\
MIGS-29 & Sequencing platforms & one 454 PE library (10 kb insert size), one Illumina library \\
MIGS-31.2 & Sequencing coverage & 60.1 $\times$ Illumina; 44.4 $\times$ pyrosequence \\
MIGS-30 & Assemblers & Newbler version 2.1-PreRelease-4-28-2009-gcc-3.4.6-threads, \\
& Gelvet, phrap \\
MIGS-32 & Gene calling method & Prodigal 1.4, GenePRIMP \\
& INSDC ID & CP002349 (chromosome) \\
& Genbank Date of Release & December 7, 2010 \\
& GOLD ID & Gc01555 \\
& NCBI project ID & 37901 \\
& Database: IMG-GEBA & 2503538019 \\
& Source material identifier & DSM 4126 \\
& Project relevance & Tree of Life, GEBA \\
\hline
\end{tabular}

\section{Growth conditions and DNA isolation}

M. tractuosa $\mathrm{H}-43^{\mathrm{T}}$, DSM 4126, was grown in DSMZ medium 172 (Cytophaga (marine) medium) [25] at $25^{\circ} \mathrm{C}$. DNA was isolated from $0.5-1 \mathrm{~g}$ of cell paste using MasterPure Gram-positive DNA purification kit (Epicentre MGP04100) following the standard protocol as recommended by the manufacturer with modification st/DL for cell lysis as described in $\mathrm{Wu}$ et al. [24]. DNA is available through the DNA Bank Network [26,27].

\section{Genome sequencing and assembly}

The genome was sequenced using a combination of Illumina and 454 sequencing platforms. All general aspects of library construction and sequencing can be found at the JGI website [28]. Pyrosequencing reads were assembled using the Newbler assembler version 2.1-Pre-release-4-282009-gcc-3.4.6-threads (Roche). The initial Newbler assembly consisted of 115 contigs in one scaffold and was converted into a phrap [29] assembly by making fake reads from the consensus, collecting the read pairs in the 454 paired end library. Illumina GAii sequencing data (496 Mb) was assembled with Velvet [30] and the consensus sequences were shredded into $1.5 \mathrm{~kb}$ overlapped fake reads and assembled together with the 454 data. The 454 draft assembly was based on 201.9 $\mathrm{Mb} 454$ draft data and all of the 454 paired end data. Newbler parameters are -consed -a 50 -l 350 -g -m -ml 20. The Phred/Phrap/Consed software package [29] was used for sequence assembly and quality assessment in the following finishing process. After the shotgun stage, reads were assembled with parallel phrap (High Performance Software, LLC). Possible mis-assemblies were corrected with gapResolution [28], Dupfinisher, or sequencing cloned bridging PCR fragments with subcloning or transposon bombing (Epicentre Biotechnologies, Madison, WI) [31]. Gaps between contigs were closed by editing in Consed, by PCR and by Bubble PCR primer walks (J.-F.Chang, unpublished). A total of 336 additional reactions were necessary to close gaps and to raise the quality of the finished sequence. Illumina reads were also used to correct potential base errors and increase consensus quality using a software Polisher developed at JGI [32]. The error rate of the completed genome sequence is less than 1 in 100,000 . Together, the combination of the Illumina and 454 sequencing platforms provided $104.5 \times$ coverage of the genome. Final assembly contains 589,653 pyrosequence and 7,543,442 Illumina reads.

\section{Genome annotation}

Genes were identified using Prodigal [33] as part of the Oak Ridge National Laboratory genome annotation pipeline, followed by a round of manual curation using the JGI GenePRIMP pipeline [34]. The predicted CDSs were translated and used to search the National Center for Biotechnology Information (NCBI) nonredundant database, UniProt, TIGRFam, Pfam, PRIAM, KEGG, COG, and In- 
terPro databases. Additional gene prediction analysis and functional annotation was performed within the Integrated Microbial Genomes - Expert Review (IMG-ER) platform [35].

\section{Genome properties}

The genome consists of a 4,511,574 bp long chromosome with a $35.5 \% \mathrm{G}+\mathrm{C}$ content and a $4,916 \mathrm{bp}$ plasmid with $40 \% \mathrm{G}+\mathrm{C}$ content (Figure 3 and
Table 3). Of the 3,857 genes predicted, 3,808 were protein-coding genes, and 49 RNAs; Fifty-one pseudogenes were identified. The majority of the protein-coding genes (62.2\%) were assigned with a putative function while the remaining ones were annotated as hypothetical proteins. The distribution of genes into COGs functional categories is presented in Table 4.

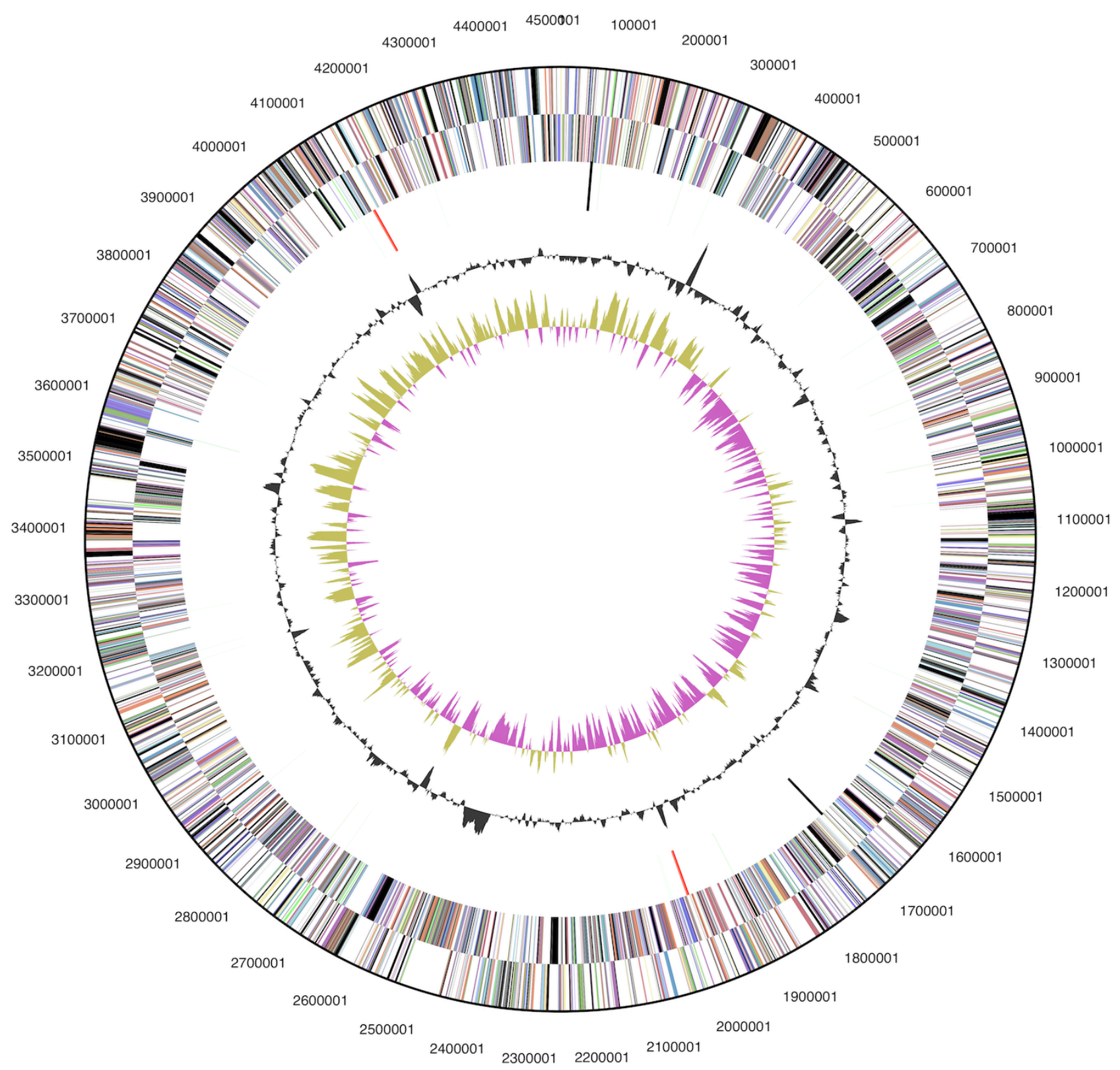

Figure 3. Graphical circular map of the chromosome (plasmid map not shown). From outside to the center: Genes on forward strand (color by COG categories), Genes on reverse strand (color by COG categories), RNA genes (tRNAs green, rRNAs red, other RNAs black), GC content, GC skew. 
Table 3. Genome Statistics

\begin{tabular}{lrr}
\hline Attribute & Value & \% of Total \\
\hline Genome size (bp) & $4,516,490$ & $100.00 \%$ \\
DNA coding region (bp) & $4,029,412$ & $89.22 \%$ \\
DNA G+C content (bp) & $1,604,111$ & $35.52 \%$ \\
Number of replicons & 2 & \\
Extrachromosomal elements & 1 & \\
Total genes & 3,857 & $100.00 \%$ \\
RNA genes & 49 & $1.27 \%$ \\
rRNA operons & 2 & \\
Protein-coding genes & 3,808 & $98.73 \%$ \\
Pseudo genes & 51 & $1.32 \%$ \\
Genes with function prediction & 2,398 & $62.17 \%$ \\
Genes in paralog clusters & 396 & $10.27 \%$ \\
Genes assigned to COGs & 2,375 & $61.58 \%$ \\
Genes assigned Pfam domains & 2,609 & $67.64 \%$ \\
Genes with signal peptides & 1,113 & $28.86 \%$ \\
Genes with transmembrane helices & 997 & $25.85 \%$ \\
CRISPR repeats & 0 & \\
\hline
\end{tabular}

Table 4. Number of genes associated with the general COG functional categories

\begin{tabular}{lrrl}
\hline Code & value & \% age & Description \\
\hline J & 157 & 6.1 & Translation, ribosomal structure and biogenesis \\
A & 0 & 0.0 & RNA processing and modification \\
K & 163 & 6.3 & Transcription \\
L & 131 & 5.1 & Replication, recombination and repair \\
B & 1 & 0.1 & Chromatin structure and dynamics \\
D & 30 & 1.2 & Cell cycle control, cell division, chromosome partitioning \\
Y & 0 & 0.0 & Nuclear structure \\
V & 63 & 2.4 & Defense mechanisms \\
T & 184 & 7.1 & Signal transduction mechanisms \\
M & 236 & 9.1 & Cell wall/membrane/envelope biogenesis \\
N & 10 & 0.4 & Cell motility \\
Z & 1 & 0.0 & Cytoskeleton \\
W & 0 & 0.0 & Extracellular structures \\
U & 37 & 1.4 & Intracellular trafficking and secretion, and vesicular transport \\
O & 112 & 4.3 & Posttranslational modification, protein turnover, chaperones \\
C & 126 & 4.9 & Energy production and conversion \\
G & 102 & 3.9 & Carbohydrate transport and metabolism \\
E & 217 & 8.4 & Amino acid transport and metabolism \\
F & 67 & 2.6 & Nucleotide transport and metabolism \\
H & 118 & 4.6 & Coenzyme transport and metabolism \\
I & 99 & 3.8 & Lipid transport and metabolism \\
P & 136 & 5.3 & Inorganic ion transport and metabolism \\
Q & 51 & 2.0 & Secondary metabolites biosynthesis, transport and catabolism \\
R & 340 & 13.1 & General function prediction only \\
S & 208 & 8.0 & Function unknown \\
- & 1,482 & 38.4 & Not in COGs \\
\hline
\end{tabular}




\section{Acknowledgements}

We would like to gratefully acknowledge the help of Maren Schröder for growing M. tractuosa cultures and Susanne Schneider for DNA extraction and quality analysis (both at DSMZ). This work was performed under the auspices of the US Department of Energy Office of Science, Biological and Environmental Research Program, and by the University of California, Lawrence Berkeley National Laboratory under contract No. DE-

\section{References}

1. Nedashkovskaya OI, Vancanneyt M, Kim SB, Bae KS. Reclassification of Flexibacter tractuosus (Lewin 1969) Leadbetter 1974 and 'Microscilla sericea' Lewin 1969 in the genus Marivirga gen. nov. as Marivirga tractuosa comb. nov. and Marivirga sericea nom. rev., comb. nov. Int / Syst Evol Microbiol 2010; 60:1858-1863. PubMed doi:10.1099/ijs.0.016121-0

2. Lewin RA, Lounsbery DM. Isolation, cultivation and characterization of flexibacteria. / Gen Microbiol 1969; 58:145-170. PubMed

3. Lewin RA. A classification of flexibacteria. / Gen Microbiol 1969; 58:189-206. PubMed

4. Leadbetter ER. 1974.Genus II. Flexibacter Soriano 1945, 92, Lewin 1969, 192 emend. mut. char. In: Buchanan RE, Gibbons NE (eds), Bergey's Manual of Determinative Bacteriology, Eighth Edition, The Williams and Wilkins Co., Baltimore, p. 105-107.

5. American Type Culture Collection. http://www.atcc.org

6. National Collection of Industrial Bacteria http://www.ncimb.com

7. Castresana J. Selection of conserved blocks from multiple alignments for their use in phylogenetic analysis. Mol Biol Evol 2000; 17:540-552. PubMed

8. Lee C, Grasso C, Sharlow MF. Multiple sequence alignment using partial order graphs. Bioinformatics 2002; 18:452-464. PubMed doi:10.1093/bioinformatics/18.3.452

9. Stamatakis A, Hoover P, Rougemont J. A rapid bootstrap algorithm for the RAxML web servers. Syst Biol 2008; 57:758-771. PubMed doi:10.1080/10635150802429642

10. Pattengale ND, Alipour M, Bininda-Emonds ORP, Moret BME, Stamatakis A. How many bootstrap replicates are necessary? Lect Notes Comput Sci 2009; 5541:184-200. doi:10.1007/978-3-642$\underline{02008-7 \quad 13}$
AC02-05CH11231, Lawrence Livermore National Laboratory under Contract No. DE-AC52-07NA27344, and Los Alamos National Laboratory under contract No. DEAC02-06NA25396, UT-Battelle and Oak Ridge National Laboratory under contract DE-AC05-000R22725, as well as German Research Foundation (DFG) INST 599/1-2.

11. Liolios K, Mavromatis K, Tavernarakis N, Kyrpides NC. The Genomes On Line Database (GOLD) in 2007: status of genomic and metagenomic projects and their associated metadata. Nucleic Acids Res 2008; 36:D475-D479. PubMed doi:10.1093/nar/gkm884

12. Nakagawa Y, Sakane T, Suzuki M, Hatano K. Phylogenetic structure of the genera Flexibacter, Flexithrix, and Microscilla deduced from $16 \mathrm{~S}$ rRNA sequence analysis. J Gen Appl Microbiol 2002; 48:155-165. PubMed doi:10.2323/jgam.48.155

13. Walsh DA, Zaikova E, Howes CG, Song YC, Wright JJ, Tringe SG, Tortell PD, Hallam SJ. Metagenome of a versatile chemolithoautotroph from expanding oceanic dead zones. Science 2009; 326:578-582. PubMed doi:10.1126/science.1175309

14. DeSantis TZ, Hugenholtz $P$, Larsen N, Rojas M, Brodie E, Keller K, Huber T, Dalevi D, Hu P, Andersen G. Greengenes, a chimera-checked 16S rRNA gene database and workbench compatible with ARB. Appl Environ Microbiol 2006;

72:5069-5072. PubMed doi:10.1128/AEM.03006-05

15. Porter MF. An algorithm for suffix stripping. Program: electronic library and information systems 1980; 14:130-137. doi:10.1108/eb046814

16. Field D, Garrity G, Gray T, Morrison N, Selengut J, Sterk P, Tatusova T, Thomson N, Allen MJ, Angiuoli SV, et al. The minimum information about a genome sequence (MIGS) specification. Nat Biotechnol 2008; 26:541-547. PubMed doi:10.1038/nbt1360

17. Woese CR, Kandler O, Wheelis ML. Towards a natural system of organisms: proposal for the domains Archaea, Bacteria, and Eucarya. Proc Natl Acad Sci USA 1990; 87:4576-4579. PubMed doi:10.1073/pnas.87.12.4576

18. Garrity GM, Holt JG. 2001. Taxonomic Outline of the Archaea and Bacteria. In: Garrity GM, Boone 
DR, Castenholz RW (eds), Bergey's Manual of Systematic Bacteriology, Second Edition, Volume 1, Springer, New York, p. 155-166.

19. Garrity GM, Holt JG. The Road Map to the Manual. In: Garrity GM, Boone DR, Castenholz RW (eds), Bergey's Manual of Systematic Bacteriology, Second Edition, Volume 1, Springer, New York, 2001, p. 119-169

20. Classification of bacteria and archaea in risk groups. http://www.baua.de TRBA 466.

21. Ashburner M, Ball CA, Blake JA, Botstein D, Butler H, Cherry JM, Davis AP, Dolinski K, Dwight SS, Eppig JT, et al. Gene Ontology: tool for the unification of biology. Nat Genet 2000; 25:25-29. PubMed doi:10.1038/75556

22. Srinivas TNR, Anil Kumar P, Madhu S, Sunil B, Sharma TVRS, Shivaji S. Cesiribacter andamanensis gen. nov., sp. nov., a novel bacterium isolated from a soil sample of a mud volcano, Andaman Islands, India. Int J Syst Evol Microbiol 2010; (In press). PubMed doi:10.1099/ijs.0.025429-0

23. Klenk HP, Göker M. En route to a genome-based classification of Archaea and Bacteria? Syst Appl Microbiol 2010; 33:175-182. PubMed doi:10.1016/j.syapm.2010.03.003

24. Wu D, Hugenholtz P, Mavromatis K, Pukall R, Dalin E, Ivanova NN, Kunin V, Goodwin L, Wu $M$, Tindall BJ, et al. A phylogeny-driven genomic encyclopaedia of Bacteria and Archaea. Nature 2009; 462:1056-1060. PubMed doi:10.1038/nature08656

25. List of growth media used at DSMZ: http://www.dsmz.de/microorganisms/media_list.p hp.

26. Gemeinholzer B, Dröge G, Zetzsche H, Haszprunar G, Klenk HP, Güntsch A, Berendsohn WG, Wägele JW. The DNA Bank Network: the start from a German initiative. Biopreservation and
Biobanking 2011; 9:51-55.

doi:10.1089/bio.2010.0029

27. DNA bank Network. http://www.dnabanknetwork.org

28. DOE Joint Genome Institute. http://www.jgi.doe.gov

29. Phrap and Phred for Windows. MacOS, Linux, and Unix. http://www.phrap.com

30. Zerbino DR, Birney E. Velvet: algorithms for de novo short read assembly using de Bruijn graphs. Genome Res 2008; 18:821-829. PubMed doi:10.1101/gr.074492.107

31. Sims D, Brettin T, Detter J, Han C, Lapidus A, Copeland A, Glavina Del Rio T, Nolan M, Chen F, Lucas $\mathrm{S}$, et al. Complete genome sequence of $K y$ tococcus sedentarius type strain $\left(541^{\top}\right)$. Stand Genomic Sci 2009; 1:12-20. PubMed doi:10.4056/sigs.761

32. Lapidus A, LaButti K, Foster B, Lowry S, Trong S, Goltsman E. POLISHER: An effective tool for using ultra short reads in microbial genome assembly and finishing. AGBT, Marco Island, FL, 2008.

33. Hyatt D, Chen GL, LoCascio PF, Land ML, Larimer FW, Hauser LJ. Prodigal: prokaryotic gene recognition and translation initiation site identification. BMC Bioinformatics 2010; 11:119. PubMed doi:10.1186/1471-2105-11-119

34. Pati A, Ivanova N, Mikhailova N, Ovchinikova G, Hooper SD, Lykidis A, Kyrpides NC. GenePRIMP: A gene prediction improvement pipeline for microbial genomes. Nat Methods 2010; 7:455-457. PubMed doi:10.1038/nmeth.1457

35. Markowitz VM, Ivanova NN, Chen IMA, Chu K, Kyrpides NC. IMG ER: a system for microbial genome annotation expert review and curation. Bioinformatics 2009; 25:2271-2278. PubMed $\underline{\text { doi:10.1093/bioinformatics/btp393 }}$ 